opium is considered by Von Graefe as a specific in the $d r y$ form of conjunctivitis. Amongst the derivatives might still have been mentioned the frequent application, but lightly made, of the mitigated lapis or the concentrated lead vinegar (solution of basic acetate of lead) to the cutaneous surface of the upper lid; but, above all, the almost stereotyped use, in acute inflammation attended with more or less intolerance of light, for inunction to the forehead, of Arlt's salve, containing the extract of belladonna and the white precipitate of mercury in varying doses (in most cases respectively one and two parts to twelve of fat. In the administration of this ointment, it is not the specific action of the ingredients which is sought; the remedy appears, in the main, to be intended as a sedative and counterirritant, and is usually directed to be applied in tolerably large quantity from six to eight times a day. The practice of ordering bulky lotions does not prevail at the Clinique; the most frequent prescription is that of two drachms of the acetum plumbi, of which a few drops mixed with a few ounces of water furnish a lead lotion to the patient which he may thus frequently renew for himself. Of very general extemporaneous employment are the elegantly prepared glycerine and starch ointments (Simon's), with their admixtures of sulphate of atropia or acetate of lead or nitrate of silver. Tar is another local application ever at hand for cases of exanthematous lid-affection.

We conclude this survey of the pharmacological armoury with a reference to some of the principal instruments of treatment relied upon by Von Graefe. Sustained pain after operation is invariably met by the subcutaneous injection of morphia; iced compresses are the chief remedy opposed to the diphtheritic process during its yet unbroken severity, and are likewise resorted to when cutaneous inflam. mation rises to an excessive height. But the great adjuvant in the subjugation of danger, or in the conquest of a partial effect at least, is the systematic use of compression, in many instances alternating with warm camomile fomentations, of a temperature regulated in accordance with the requirements of the cases. It is this latter method of proceeding matured to its present perfection by the thoughtful and assiduous study of many years, and ever and anon, in the individual cases, practised with unswerving vigilance, which, in our opinion, again constitutes one of those patent secrets of success attending the practice of a master of the healing art.

If, by way of transition to the chapter of operations proper, I shortly refer to those multiform manipulations which in a sense belong to the province of what is called minor surgery, as they are mostly performed in a more off-hand way-such as the opening of abscesses, or of the lacrymal ducts after Weber's method, ar the abscission of prolapsed iris-it is because Von Graefe's systematic dealing with the last-named morbid occurrence has appeared to me so pre-eminently instructive. In those frequent instances of ulcerative perforation of the cornea, whether of diptheritic or blennorrhoic origin, the luxuriating protuberance is never winked at, but again and again remored with scissors, until, in progress of time and by dint of cauterisation of the mucous membrane, the exuberant tendency of the morbid process, if not an invariably destructive one, is effectually subdued. It is once more our impression that diligence and devotion thus succeed in rescuing much that else would be unfailingly lost; and the least gain is a more speedy termination of the process.

[To be continued.]

\section{DESCRIPTION OF A KIDNEY, WITH} CYST, CONTAINING CALCULI.

By G. H. Philipson, M.A., M.D.Cantab., M.R.C.P., Newcastle-upon-Tyne.

THE kidney was taken from a sailor, a patient in the Newcastle Infirmary, under the care of Dr. Humble, who kindly permitted me to make the post mortem examination, and the further privilege of giving the following description.

The organ, when removed, was of ordinary size and natural in appearance, the capsule being removed with ease. When divided by a longitudinal incision, the lower third was found hollowed into a cavity, filled with serous fluid, and containing four calculi; the remaining portion being healthy, the cortical substance well distinguished from the medullary. The cavity was equal in size to a large walnut, internally ridged, lined with a glistening white membrane, and for two-thirds of its circumference bordered and separated from the capsule by the cortical structure, fully one-fifth of an inch in thickness. No communication existed between the cavity and infundibula, which, with the pelvis and ureter, were of ordinary capacity and free from calculi. The fluid was clear, colourless, and devoid of any urinous odour. The calculi together weighed nine grains. Two were like small peas; the others larger, nodous, with two or three prolongations. The section of one of the small ones disclosed a distinct nucleus, surrounded by visible layers. Chemically, it was composed of oxalate of lime.

The right kidney was healthy. The pleuræ were firmly adherent; the lungs highly emphysematous ; the bronchial tubes filled with tenacious mucus; and the mucous membrane extensively inflamed-the immediate cause of death.

Cavities or cysts in the kidney, perfectly distinct from the pelvis, and filled with serous fluid, are not unfrequently observed; but, containing calculi, very rarely so-the renal calculus being commonly located within the pelvis or the cyst-like expansion formed by the dilatation of an infundibulum.

The obstruction of a tube, and the extension of the pervious portion, from the collection of fluid, is applicable as an explanation of the origin of the cyst ; the calculi, in all probability, being subsequently formed by deposition upon some urinary or organic matter within the tube.

A Wonderful Bullet. I had just been ordering our men not to waste their ammunition, and to fire only when they saw the person of a Yankee completely exposed, when close at hand I heard the dull thud of a bullet striking home, and turning round I saw one of our soldiers, a gallant young fellow whom I knew well, throw up his arms and fall heavily to the ground. Dismounting at once, I hastened to his side; but finding that the ball had struck him right in the middle of the forehead I regarded him as a corpse, and deemed all further assistance wholly unnecessary. Not many minutes had elapsed, however, before the apparently dead man began to move, and when the surgeon, who had already arrived, poured some brandy down his throat, to our infinite amazement he opened his eyes. A few hours later, miraculous to relate, when the bleeding from the wound had ceased, he had recovered sufficiently from the severe shock to return to his post of duty. According to the surgeon's statement, the ball, striking obliquely, had glanced, passing between cuticle and skull, all around the head, emerging at last from the very place it had first entered. (Blackwood's Magazine.) 